Florida International University FIU Digital Commons

FIU Electronic Theses and Dissertations

University Graduate School

6-16-2015

\title{
An Analysis of Evacuation Behavior During Hurricane Ike
}

YuanYuan Lu

Florida International University, ylu013@fiu.edu

DOI: $10.25148 /$ etd.FIDC000121

Follow this and additional works at: https://digitalcommons.fiu.edu/etd

Cart of the Behavioral Economics Commons

\section{Recommended Citation}

Lu, YuanYuan, "An Analysis of Evacuation Behavior During Hurricane Ike" (2015). FIU Electronic Theses and Dissertations. 2179. https://digitalcommons.fiu.edu/etd/2179

This work is brought to you for free and open access by the University Graduate School at FIU Digital Commons. It has been accepted for inclusion in FIU Electronic Theses and Dissertations by an authorized administrator of FIU Digital Commons. For more information, please contact dcc@fiu.edu. 


\section{FLORIDA INTERNATIONAL UNIVERSITY}

Miami, Florida

AN ANALYSIS OF EVACUATION BEHAVIOR DURING HURRICANE IKE

A thesis submitted in partial fulfillment of the requirements for the degree of MASTER OF SCIENCE

in STATISTICS

by

Yuan Yuan Lu

2015 


\title{
To: Dean Michael R. Heithaus
}

College of Arts and Sciences

This thesis, written by Yuan Yuan Lu, and entitled An Analyses of Evacuation Behavior during Hurricane Ike, having been approved in respect to style and intellectual content, is referred to you for judgment.

We have read this thesis and recommend that it be approved.

\author{
Xia Jin \\ Pallab Mozumder, Co-Major Professor \\ B M Golam Kibria, Co-Major Professor
}

Date of Defense: June 16, 2015

The thesis of Yuan Yuan Lu is approved.

Dean Michael R. Heithaus

College of Arts and Sciences

Dean Lakshmi N. Reddi

University Graduate School

Florida International University, 2015 


\section{ACKNOWLEDGMENTS}

First of all, I would like to express my sincere thanks to my Co-major professors, Dr. B M Golam Kibria and Dr. Pallab Mozumder, for their patient guidance, enthusiasm, encouragement and friendship throughout this whole study. I couldn't finish my research without their great support.

I would also like to thank the members of my committee, Dr.Florence George and Dr. Xia Jin for their time, valuable advice and great encouragement. In addition, I would like to thank National Science Foundation (Award \# 0838683) for funding and Co-PI of this project, Dr.Hugh Gladwin, for survey design and data.

Finally, I would like to express my appreciation to my parents, friends, and

all the professors, who encouraged and supported me throughout the whole studying life in Florida International University. 


\author{
ABSTRACT OF THE THESIS \\ AN ANALYSIS OF EVACUATION BEHAVIOR DURING \\ HURRICANE IKE \\ by \\ Yuan Yuan Lu \\ Florida International University, 2015 \\ Miami, Florida \\ Professor B M Golam Kibria, Co-Major Professor \\ Professor Pallab Mozumder, Co-Major Professor
}

Hurricanes have been considered one of the most costly disasters in United State, which lead to both economic loss and human fatalities. Therefore, understanding the characteristics of those who evacuated and of those who did not evacuate have been principal focus of some previous researches related to hurricane evacuation behavior. This research presents two sets of decision-making models for analyzing hurricane evacuation behavior, using two statistical methods: standard logistic model and mixed logistic model. The receipt of evacuation order, elevation, expenditure, the presence of children and elderly people, ownership of a house, and receipt of hurricane warning are found to be extremely important in evacuation decision making. When the mixed logistic model is applied, the rate of concern about hurricane threat is assumed to be random according to normal distribution. Mixed logistic models which account for the heterogeneity of household responses are found to perform better than standard logistic model. 


\section{TABLE OF CONTENTS}

CHAPTER

PAGE

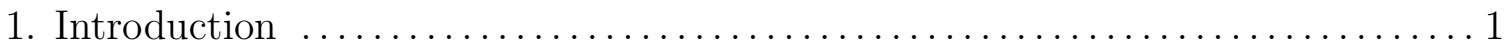

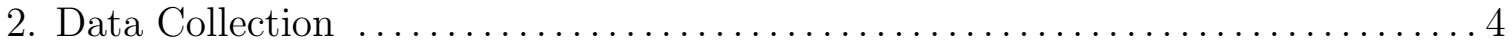

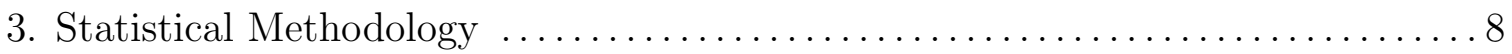

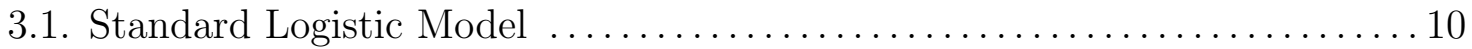

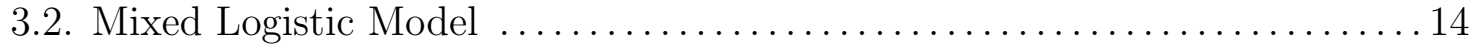

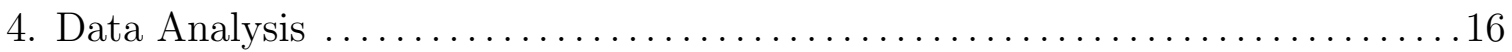

4.1. Standard Logistic Model Result . ............................ 17

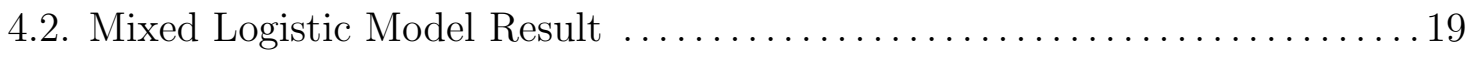

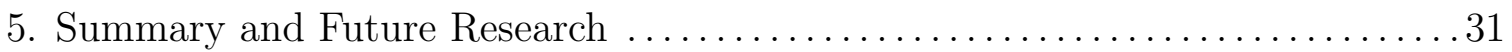

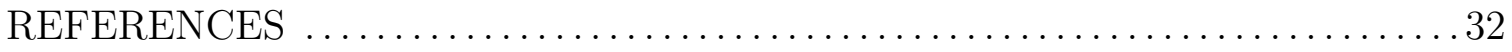




\section{LIST OF TABLES}

TABLE

PAGE

1. Description and Summary Statistics of the Variables $\ldots \ldots \ldots \ldots \ldots \ldots \ldots \ldots$

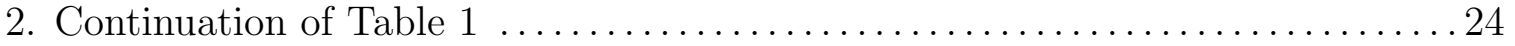

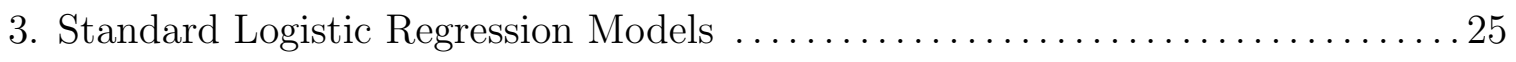

4. Summary of Standard Logistic Regression Models $\ldots . \ldots \ldots \ldots \ldots \ldots \ldots \ldots$

5. Mixed Logistic Regression Models .................................27

6. Summary of Mixed Logistic Regression Models $\ldots \ldots \ldots \ldots \ldots \ldots \ldots \ldots \ldots$ 


\section{LIST OF FIGURES}

FIGURE

PAGE

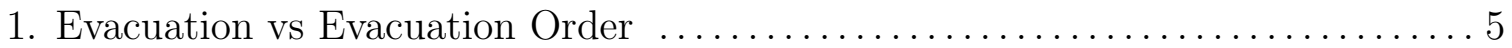

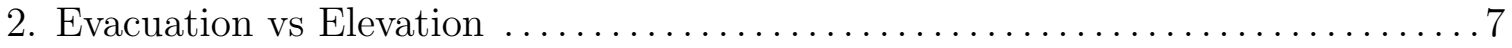

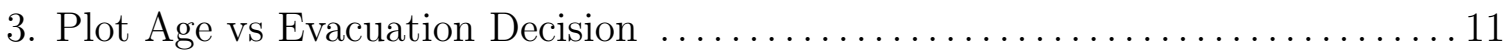

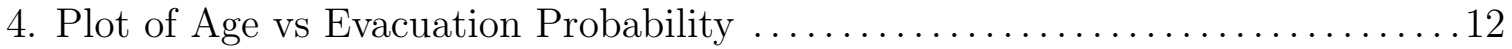

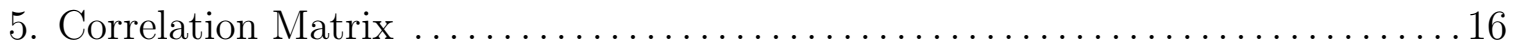

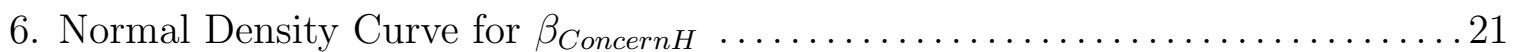

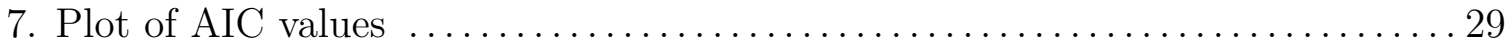

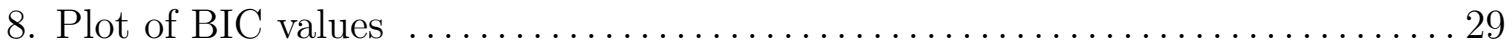

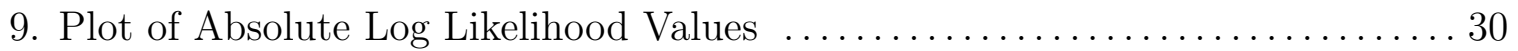

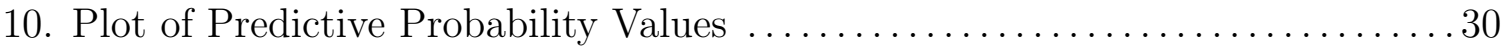




\section{Introduction}

One of the most destructive natural disasters, the hurricane, has caused considerable damage to coastal communities, as it came along with strong winds, storm surges and flooding. The decade from 1996 to 2005 was the one of the most destructive in the last century. Damages from those storms were estimated to be $\$ 198$ billion (Hasan et al. 2010). Rita in 2005 alone led to approximately $\$ 10$ billion (Pielke et al. 2008) damage to property.

The protection technologies against hurricanes have improved significantly over the past decade, driven by an intensely destructive period of hurricane activity. The 2000 International Residential and Commercial Building Codes required the use of impact-resistant windows, doors and other components for houses built in hurricaneprone areas for the first time (Cox et al. 2006). The prevailing Building Codes mainly focused on building exteriors. New houses built in Florida within the area where 120 mph winds or greater are expected must have exterior impact protection (Dehring et al. 2013). Examples of hurricane impact protection include impact resistant windows, hurricane shutters and reinforced doors.

Despite the development of hurricane protection technologies, the effect of Hurricane Ike in Texas was still crippling and long-lasting. Hurricane Ike was the most harmful Atlantic storm in 2008 (Pan et al. 2012). It made landfall in Texas at the north end of Galveston Island on September 13, 2008. It sent a 10- to 15-foot storm surge into Galveston and parts of the western end of Galveston bay, and up to a 20-foot surge over the Bolivar Peninsula and parts of Chambers Country, Texas. 
Ike smashed residential houses, flooded commercial buildings, damaged transport facilities and utility services. Ike not only caused economic loss which will last for a long time after hurricane, but also caused many fatalities. More than 100 residents died in United States as a result of Ike. Considering the damage caused by hurricanes, understanding the characteristics of those who evacuated and of those who did not evacuate have been principal focus of many previous researches. (Baker 1979; Cross 1979; Baker 1991; Fischer et al. 1995; Dow and Cutter 1998; Drabek 1999). A recent review by Dash and Gladwin (2007) concluded that several important factors are found to influence a household's decision to evacuate or stay at home. These factors include presence of children and elderly persons in a household, age of the decision maker, disability, gender, race, income, previous experience, and location.

Whitehead et al. (2000) consider environmental factors, storm intensity (by presenting hypothetical storm scenarios to respondents), besides social and demographic factors, in developing an evacuation model. They found that the important predictor of evacuation is storm intensity. Households are more likely to evacuate when given evacuation orders, and when they live in mobile home. Compared with perceived risk from wind, perceived risk from flooding is more important in evacuation decision. One the other hand, non-white households, pet owners and those with more education prefer to stay at home with family or friends, instead of evacuating.

My research objectives are to develop household's evacuation decision models based on both standard logistic method and mixed logistic method, and then compare the results between two methods. In addition, my research find the important factors 
in decision making and reveals the influence of those factors to evacuation decision. Several factors which are reported in my research are consistent with previous findings. The organization of the thesis is as follows: The data collection technique has been discussed in Chapter 2. Chapter 3 contains the statistical methodology. Data are analyzed and discussed the results in Chapter 4. This thesis ends with summary and future research in Chapter 5. 


\section{Data Collection}

My research data were collected by a telephone survey. In 2010, the Social Science Research Lab at the International Hurricane Research Center at Florida International University conducted 1,099 telephone interviews from a random probability sample of households located in Harris and Galveston counties in Texas with a response rate of 36 percent. A geocoded zip codes area stratified sampling frame was used to oversample areas of higher storm surge risk. More interviews were done proportionally in zip code areas that are lower elevation and near to the coast.

The survey questionnaire asked about the behavior adopted by respondents to minimize the risk of being affected by hurricane, specifically hurricane Ike when it hit the coast of Texas. One of the survey questions asked the following question:

Did you evacuate for hurricane Ike, or did you stay in your home? STAYED

\section{IN HOME or EVACUATED}

The binary response of the question works as the dependent variable Evacuation in my analysis (Evacuation $=1$, if evacuated or Evacuation=0, if stayed at home). Respondents who evacuated were asked a sequence of questions related to evacuation, such as evacuation time, transportation, duration, preparation and evacuation expenditure. Respondents who did not evacuate were also asked to state the expenditure that they would spend if they had evacuated before hurricane.

The last part of the survey, designed for all participants, gathered information of the explanatory variables for predicting evacuation decision. The survey asked respondents whether they prepared window protection or elevated their houses before 
hurricane came. Respondents were also asked to report whether their houses were damaged because of hurricane and how much damage the hurricane brought to their house. Furthermore, the questionnaire asked respondents whether their neighborhood got any evacuation order before hurricane and if they did, what the type of evacuation order they got (Voluntary Order or Mandatory Order). Figure 1 displays the geocoded locations of survey households which are differentiated by the type of evacuation order and evacuation decision. Visually, the percentage of evacuated households with mandatory evacuation order is higher than the percentage of evacuation with voluntary evacuation order.

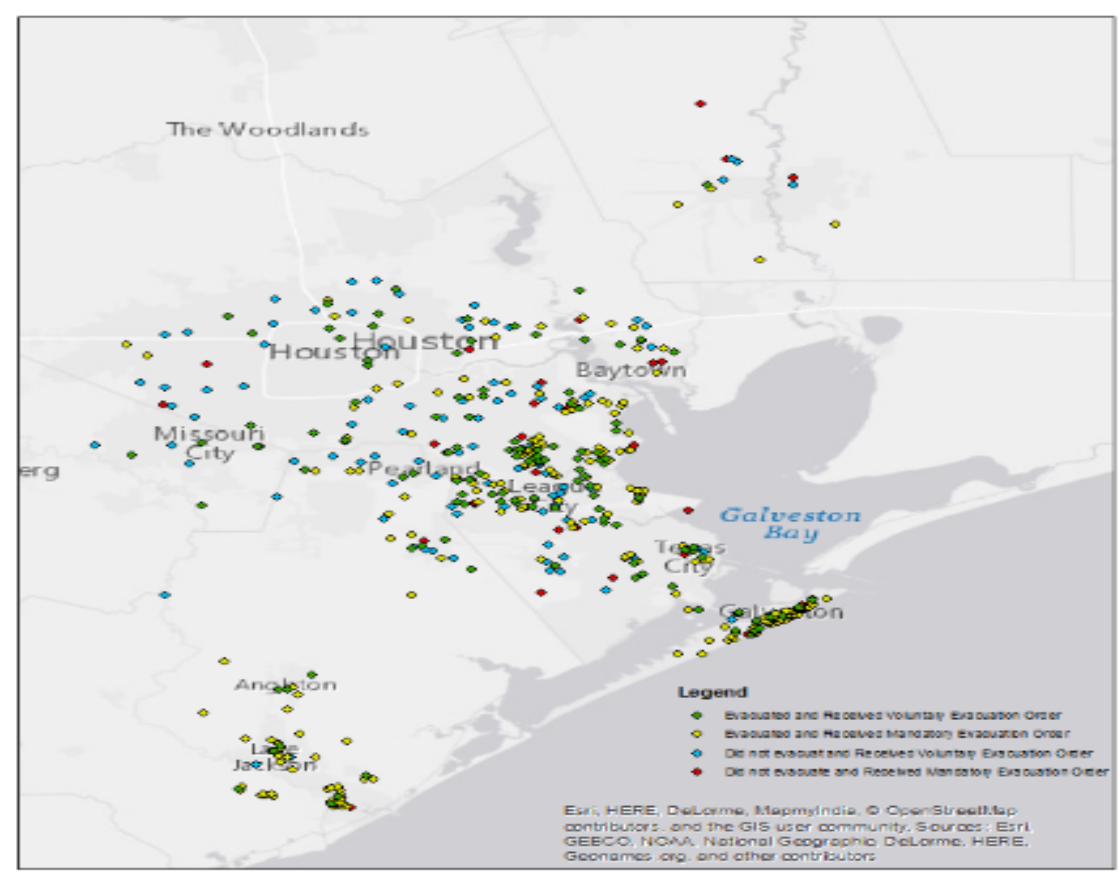

Figure 1: Evacuation vs Evacuation Order

Respondents were also asked how their pet affected their evacuation decision and the degree of their concern about the damage of hurricane Ike. Finally, our re- 
search collected information about socioeconomic characteristics of respondents, such as their income level, education level and type of house occupied. Using the survey data, two spatial factors are found: household elevation and average distances from households to hurricane Ike tract. Texas elevation dataset was collected from Texas Natural Resources Information System (TNRIS). TNRIS was established by the Legislature in 1968 as the Texas Water-Oriented Data Bank. After four years of growth and diversification, it was renamed the Texas Natural Resources Information System in 1972. Average distances were calculated using longitude and latitude of households and Ike tract. The longitude and latitude data for Ike tract were found from National hurricane center. Figure 2 gives the geocoded locations of households who evacuated and households who did not evacuate, hurricane Ike tract, and household elevation. (See Table 1) 


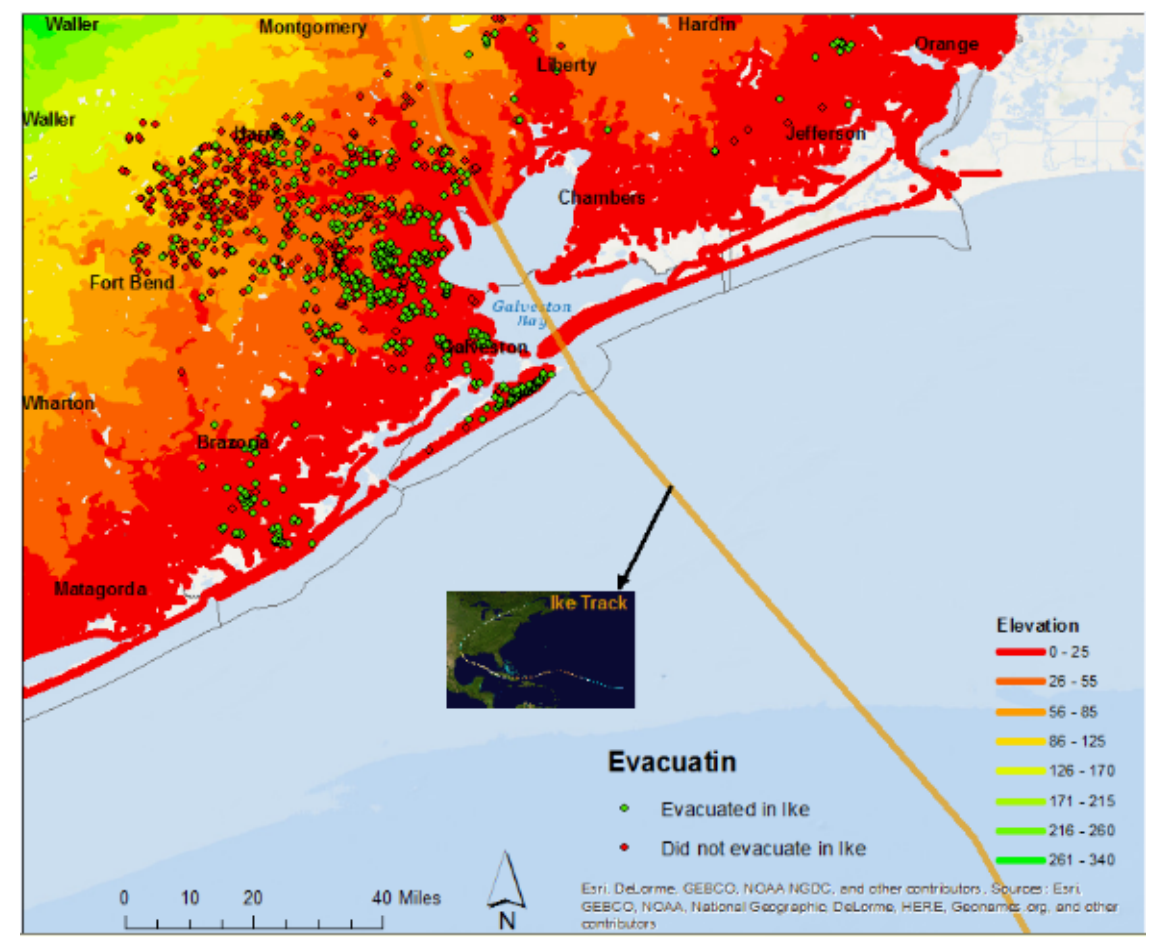

Figure 2: Evacuation vs Elevation

Clearly, there are more evacuees in the low elevation area. Even thought many evacuated households are closed to Ike tract, a small part of evacuated households in Brazoria county and Orange county actually live far from the tract. This might be one of the reasons why average spatial distance is not significant in the data. 


\section{Statistical Methodology}

Considering the binary outcomes for evacuation behavior, two discrete-outcome models were analyzed in my research: standard logistic model and mix logistic model. Standard logistic model could offer rigorous analytical framework for modeling such situations, but it also assumes the coefficients of variables are fixed across all observation (Hasan et al. 2011). When this assumption does not hold, standard logistic model will result in inconsistent parameter estimators and outcome probabilities. The concern has led many researchers to consider more flexible alternatives. Mixed logistic model, as an alternative, extends the standard conditional logistic model by allowing one or more of the parameters in the model to be randomly distributed. It allows researchers to account for both observed and unobserved heterogeneity of households response caused by a hurricane threat.

When we compare relative performance of a set of statistical models, Akaike Information Criterion (AIC) can work as a measurement for model selection. The AIC is derived from information theory and selects a model that minimizes the KullbackLeibler distance between the estimated and the true models. Given a set of models, the preferred model is the one with the minimum AIC value. The AIC value is defined as following:

$$
A I C=2 * p-2 * \ln (L),
$$

where $\mathrm{L}$ is the maximized value of the likelihood function for the model; $\mathrm{p}$ is the number of estimated parameters. While adding parameters in the model is possible to increase the likelihood, it may also result in overfitting. AIC solves the situation 
of dilemma by adding penalty, an increasing function of the number of estimated parameters, to discourage overfitting. Similar with AIC, Bayesian information criterion (BIC) or Schwarz criterion (BIC Schwarz) is another criterion with penalty term to avoid overfitting for model selection, yet, the penalty term is larger in BIC than in AIC. The BIC is formally defined as:

$$
B I C=K * \ln (n)-2 * \ln (\hat{L})
$$

where $n$ is the number of observations or sample size; $\mathrm{K}$ is the number of free parameters to be estimated; $\hat{L}$ is the maximized value of likelihood function. The model with lowest BIC value is preferred.

Except for AIC and BIC, predictive probability is also a very good criteria for model selection. Predictive probability is the probability that one statistical model successfully predict the binary outcome. In logit model, the probability of success, instead of the direct binary result, is predicted. When the predicted probability is greater than 0.5 , the outcome is assumed to be success, while failure is assumed to happen with predicted probability less than 0.5 . Then the predictive probability is defined as follows:

$$
\begin{aligned}
\text { Predictive Probability } & =\frac{\text { No. of correctly predicted Yes }}{\text { Total sample size }} \\
& +\frac{\text { No. of correctly predicted No }}{\text { Total sample size }}
\end{aligned}
$$




\subsection{Standard Logistic Model}

Many human behavior research problems call for the analysis and prediction of a dichotomous outcome, such as whether a single is prone to get married, whether a drive will choose to listen to a phone call when his or her phone is ringing during driving, whether a custom will purchase a product from the same brand next time, and so on. Before logistic regression was proposed, most of these research questions are addressed by least squares regression (OLS), which, however, was subsequently found not to be an ideal model for dealing with dichotomous outcomes due to dissatisfied assumption: errors are not normally distributed and no linear relationship exists between explanatory variables and dependent variable. Logistic regression, as an alternative to least square regression, has been increasingly used since late 1960s and early 1970s (Peng et al. 2002).

Logistic regression is well suited to describe the relationship between one dichotomous outcome and one or more categorical or continuous predict variables. However, the plot of such data always results in 2 parallel lines, which respectively corresponds to two different outcomes of dichotomous dependent variable, such as the plot of Evacuation decision and Age (see Figure 3). 


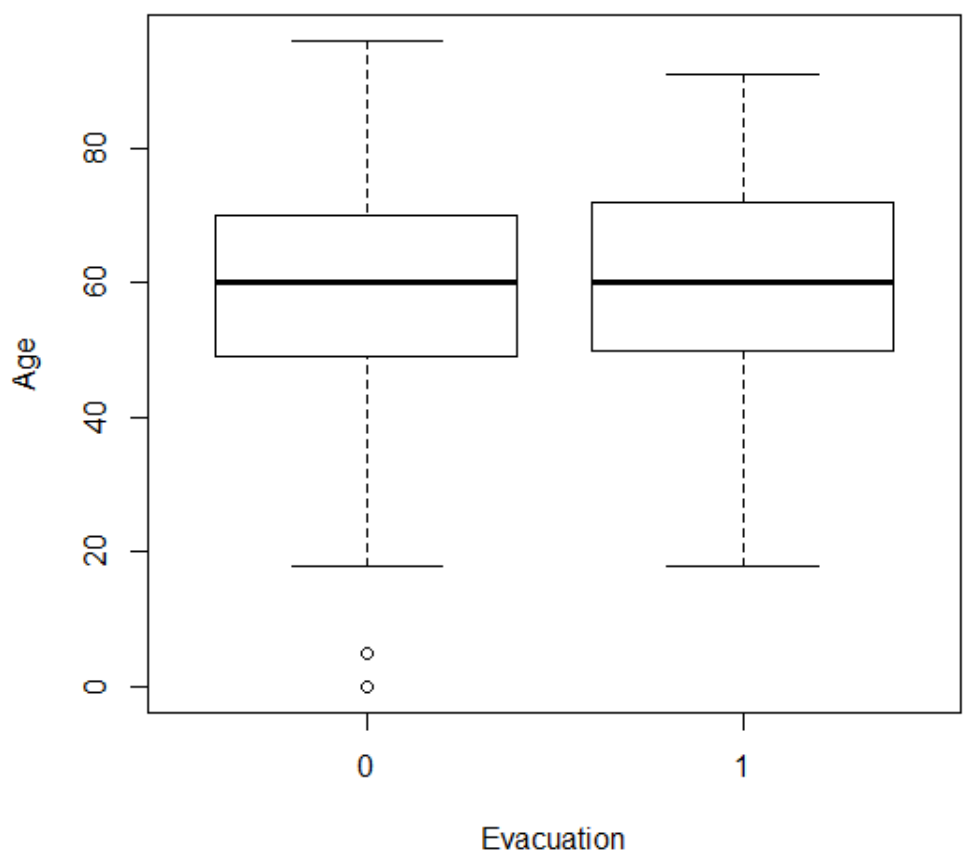

Figure 3: Plot of Age vs Evacuation Decision

Because of the binary outcomes, ordinary least square model could not be used to model the two parallel lines. Thus, researchers alternatively compute the probability of the dependent variable happening, which is also the mean of dependent variable for the respective categories. The resultant plot of probability is an S shape, with curvilinear at both ends and a line in the middle (see Figure 4). 


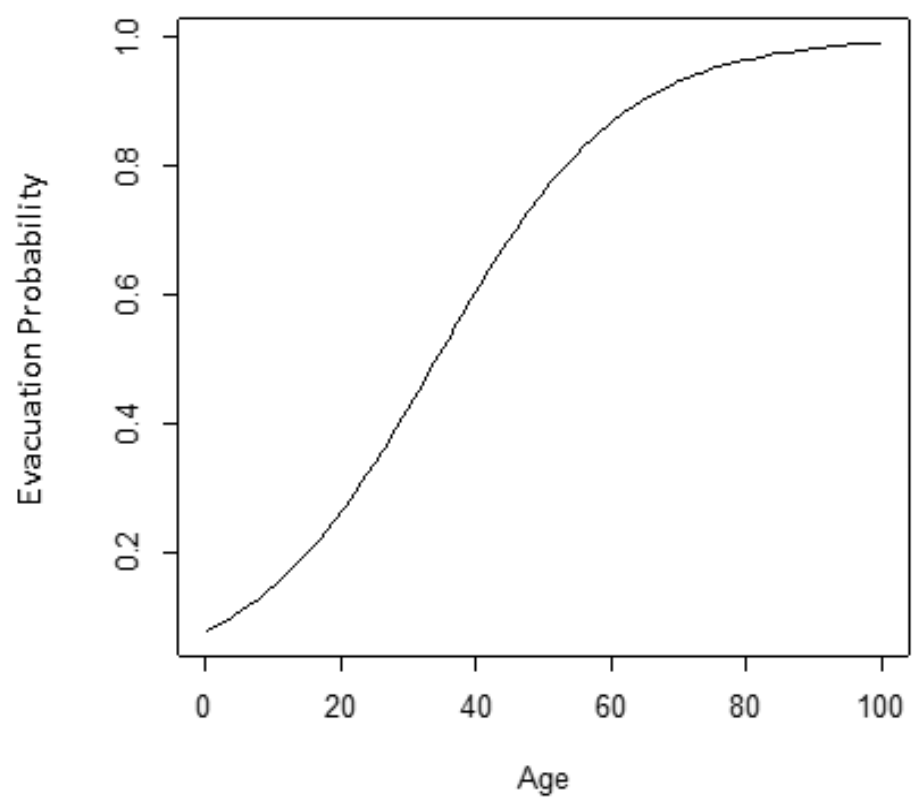

Figure 4: Plot of Age vs Evacuation Probability

Yet, ordinary least square is still not an appropriate model to describe the S shape, because that the shape does not follow linear trend at end and the error is neither normal distributed nor constant (Peng et al. 2001). Logistic regression solves these problems by predicting the natural logarithm of odds of dependent variable from independent variables. The odds of dependent variable is the ratio of the probability that dependent variable happens to the probability that dependent variable does not happen.

In my research, dichotomous outcome: evacuation decision (Evacuation) works as dependent variable, with "1" representing "Evacuated" and "0" representing "Did not evacuate". Thus, odds of evacuation is the ratio of the probability of evacuation 
to the probability of not evacuation. The logistic regression model could be described as follows:

$$
\operatorname{logit}(Y)=\text { natural } \log (\text { odds })=\ln \left(\frac{p_{i}}{1-p_{i}}\right)=\beta X_{i} i=1,2 \ldots n
$$

When taking antilog on both sides of equation (4), one derives an equation to predict the probability of the occurrence of evacuation as follows:

$$
P(Y=\text { Evacuation } \mid X=x)=\frac{e^{\beta X}}{1+e^{\beta X}},
$$

where $X$ is a vector of independent variables that influence evacuation; $\beta$ represents the conformable vector of coefficients or parameters of the model. As stated earlier, predictors include demographic factors, income, evacuation order, risk perception, and own houses or not, and so on.

The logistic regression coefficients $(\beta)$ are usually estimated by Maximum likelihood method:

$$
\begin{aligned}
L(\beta)=\prod_{i=1}^{n} p\left(x_{i}\right)^{y_{i}}\left(1-p\left(x_{i}\right)\right)^{1-y_{i}} i=1,2,3 . . n \\
\ln (L(\beta))=\sum_{i=1}^{n} y_{i} * \ln p\left(x_{i}\right)+\sum_{i=1}^{n}\left(1-y_{i}\right) * \ln \left(1-p\left(x_{i}\right)\right) \\
=\sum_{i=1}^{n} y_{i} \frac{\ln p\left(x_{i}\right)}{\ln \left(x-p\left(x_{i}\right)\right)}+\sum_{i=1}^{n} \ln \left(1-p\left(x_{i}\right)\right), i=1,2 . . n
\end{aligned}
$$

Unlike the ordinary linear regression with normal distributed error, it is not possible to find a closed-form expression for the coefficient values that maximize the likelihood function, so that an iterative process must be used instead. 


\subsection{Mixed Logistic Model}

Mixed logistic model is another method used to analyze the binary dependent variable, which account for the probability that parameters may vary across observations. Mixed logistic model has been considered as one of the most promising tool for modeling discrete choice data by many researchers. The mixed logistic probability can be derived from utility-maximizing behavior in several ways that are formally equivalent but provide different interpretations. Following the work presented in Train (2003), standard random utility theory suggests that the utility of a household n choosing an alternative $i$ is given as follows:

$$
U_{n i}=\beta_{n} X_{n i}+\epsilon_{n i}, \quad \beta_{n}, \sim f(\beta \mid \theta), i=1,2,3 . . n
$$

where $X_{n i}$ is a vector of observed variables that related to the alternatives and decision maker, which is same with previous vector of dependent variable in standard logistic model in my research; $\beta_{n}$ is a vector of coefficients of these variables for person $n ; \theta$ is the parameter for the density function of random coefficients; $\epsilon_{n i}$ is error components which may be due to unaccounted measurement error, correlation in the parameters, unobserved individual preferences, and other similar unobserved characteristics of the choice-making. $\epsilon_{n i}$ is a random term that is iid extreme value. Participants will choose alternative $\mathrm{i}$, when $U_{n i}>U_{n j}, i<>j$

When $\epsilon_{n i}$ is assumed as extreme-value Type 1 distributed, the model can be treated as a binomial logit model with two alternatives as follows:

$$
\operatorname{Prob}_{n}(i)=\frac{e^{\beta_{n} X_{n i}}}{\sum_{j=1}^{j}, e^{\beta_{n} X_{n j}}}
$$


where $\operatorname{Prob}_{n}(i)$ is the probability of household $\mathrm{n}$ evacuating; $X_{n i}$ is a vector of independent variables; $J$ is the total number of alternatives. In our case, $J$ is equal to 2 . As $\beta_{n}$ is random vector, the choice probability is the integral of equation (9) over the density of $\beta_{n}$

$$
P_{n i}=\int \operatorname{Prob}_{n}(i) f(\beta \mid \theta) d \beta
$$

This model allows the slopes of utility to be random, which is an extension of the random effects model only with random intercept. Some elements of $\beta_{n}$ may be fixed parameters or random parameters. The distribution of $\beta_{n}$ could be specified as any probability density function. The most widely used one is normal distribution, which is assumed in this research. 


\section{Data Analysis}

The description of all the variables are listed in Table 1 . We first report the correlation matrix (Figure 5) of variables used in our models.

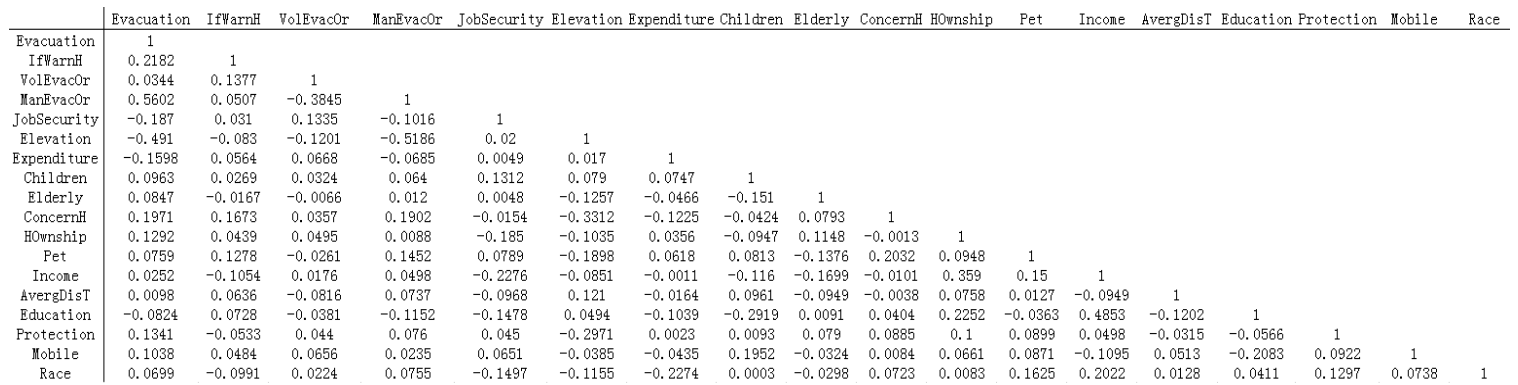

Figure 5: Correlation Matrix

As figure 5 shows that all the correlation values of any two explanatory variables are bigger than -0.5 and smaller than +0.5 , we can assume that there is no multicollinearity between any two predictors. The matrix also gives intuitive indications of relation between possible predictor and evacuation decision. For example, evacuation is negatively related with JobSecurity, Elevation, Expenditure and Education. On the other hand, evacuation is positively related with the other variables, such as the number of children and elderly person, the receipt of voluntary and mandatory evacuation order, and ownership of a house. 


\subsection{Standard Logistic Model Result}

In my research, several standard logistic models were fitted with different predictors. Of all the models, four models (reported in Table 2) were selected based on the goodness of fit criteria. The significant variables for standard logistic regression model are summarized in Table 3 .

IfWarnH represents whether respondents consider hurricane warning is helpful or not (IfWarnH=1 means Helpful, while IfWarnH=0 means Unhelpful). IfWarnH has positive effect on evacuation decision, as all the coefficients for it are positive from Model 1 to Model 4. In Model 1, $\beta_{I f W a r n H}$ is 0.486 , which means the odds ratio of IfWarnH is 1.597 , since $e^{0.468}=1.597$. In other words, the odds of evacuation for households who consider hurricane warning helpful over the odds of evacuation for households who perceive hurricane warning is useless is 1.597, which supports the conclusion that households are more likely to evacuate, when they appreciate hurricane warning.

While the receipt of evacuation order (both voluntary evacuation order and mandatory evacuation order) is statistically significant at 0.05 significant level (in Model 1 to Model 4), households receiving a mandatory evacuation order, compared with receiving a voluntary evacuation order, are more likely to evacuate, as coefficients for ManEvaOr are bigger than coefficients for VolEvacOr for all four models. For example, in Model 1, the coefficient for voluntary evacuation order is 1.631, referring that the odds ratio of VolEvacOr is equal to $5.109\left(e^{1.631}=5.109\right)$. When other predictor variables are kept fixed, the odds of evacuation with a voluntary 
evacuation order is about $410.9 \%$ higher than the odds of evacuation without a voluntary evacuation order. However, $\beta_{\text {ManEvacOr }}$ is 2.903, suggesting that the odds ratio of ManEvacOr is 18.229. When we hold other predictors fixed, we will see a $1722.9 \%$ increase of evacuation odds when mandatory evacuation orders are issued. The comparision of $410.9 \%$ with $1722.9 \%$ reinforces the statement that the notice of mandatory evacuation order has an larger effect on evacuation decision than the notice of voluntary evacuation order.

Both increasing number of children and elderly person improve the probability of household evacuation. In Model $1 \beta_{\text {Children }}=0.379$, implying odds ratio for children is equal to 1.46 . One children increase in a family leads to $46.1 \%$ increase of evacuation odds. Based on the result of Model 2, household evacuation odds increases $75.6 \%$ with one more elderly person in household, since the odds ratio of elderly is 1.756 . In addition to above factors, households who own a house, live in a mobile house, have higher income level, and concern about hurricane risk also prefer to evacuate before hurricane.

The status of unemployment because of hurricane, elevation, and evacuation expenditure, however, trend to decrease the probability of evacuation. The fact that odds ratio of JobSecurity is 0.276 implies that odds of evacuation under unemployment status is about $72.4 \%$ less than the odds under employment status in Model 1. Unlike JobSecurity, both Elevation and Expenditure are continuous. In Model 1, the coefficient for Elevation is -0.913 , referring that when holding other predictor variables fixed, we will see the $59.87 \%$ decrease in the odds of evacuation for one-unit 
increase in log-transformed elevation, since $e^{-0.913}=0.4013$. Similar with elevation, when assuming other predictor variables fixed in Model 1, we will expect $52.4 \%$ decrease in the odds of evacuation for one-unit increase in log-transformed expenditure, since $\beta_{\text {Expenditure }}=-0.742$. Except for unemployment, elevation, and evacuation expenditure, higher level of education, the presence of pet and hurricane protection and spatial distance from household to hurricane tract also have negative effects on evacuation decision.

Surprisingly, spatial distance is not significant in Model 4. As I mentioned earlier, one of the reasons might be that a small part of survey households who evacuated before hurricane live far from Ike tract. In order to get more accurate result about the influence of spatial distance to evacuation decision, more survey data might need to be collected.

Among all the standard logistic models, Model 3 has smallest AIC (showed in Figure 7), BIC (showed in Figure 8) and absolute value of log likelihood (showed in Figure 9), and largest Pseudo $R^{2}$ value and predictive probability (showed in Figure 10). These figures show that Model 3 performs better than Models 1, 2 and 4 .

\subsection{Mixed Logistic Model Result}

Using the results from standard logistic models in section 4.1, four mixed logistic regression models, with random variables chosen by their standard errors, are fitted and their results are presented in Table 4. The significant variables are summarized in Table 5. Parameters with significant standard errors are considered random, and the remaining parameters are determined as fixed, as the standard 
deviation of these parameters are not significantly different from zero. Based on my data set, only the parameter for the rate of concern about the threat of hurricane (ConcernH) has significant standard deviation and is assume to be random according to normal distribution for all mixed logistic models. All of Figures 7, 8 and 9 show that all the bars for mixed logistic models are lower than the relative bars for standard logistic models, indicating that the whole mixed logistic regression model set has a smaller AIC, BIC and absolute log likelihood values than relative logistic model set. Figure 10 also shows that mixed logistic models have larger predictive probability than normal logistic models. Therefore, for my research, mixed logistic performs better than standard logistic, in the aspect of AIC, BIC, absolute value of log likelihood and predictive probability.

Even though Model 1 and Model 5 have the same set of predictors, the ownership of a house updates its significant level in Model 5. HOwnship is significant at 0.10 significant level in Model 1, while it is significant at 0.05 significant level in Model 5. In Model 5 the rate of concern about the hurricane has a random parameter, with a mean of 0.066 and a standard deviation of 0.098 (assuming a normal distribution of parameter). Figure 6 shows the density curve of $\beta_{\text {Concern } H}$. 


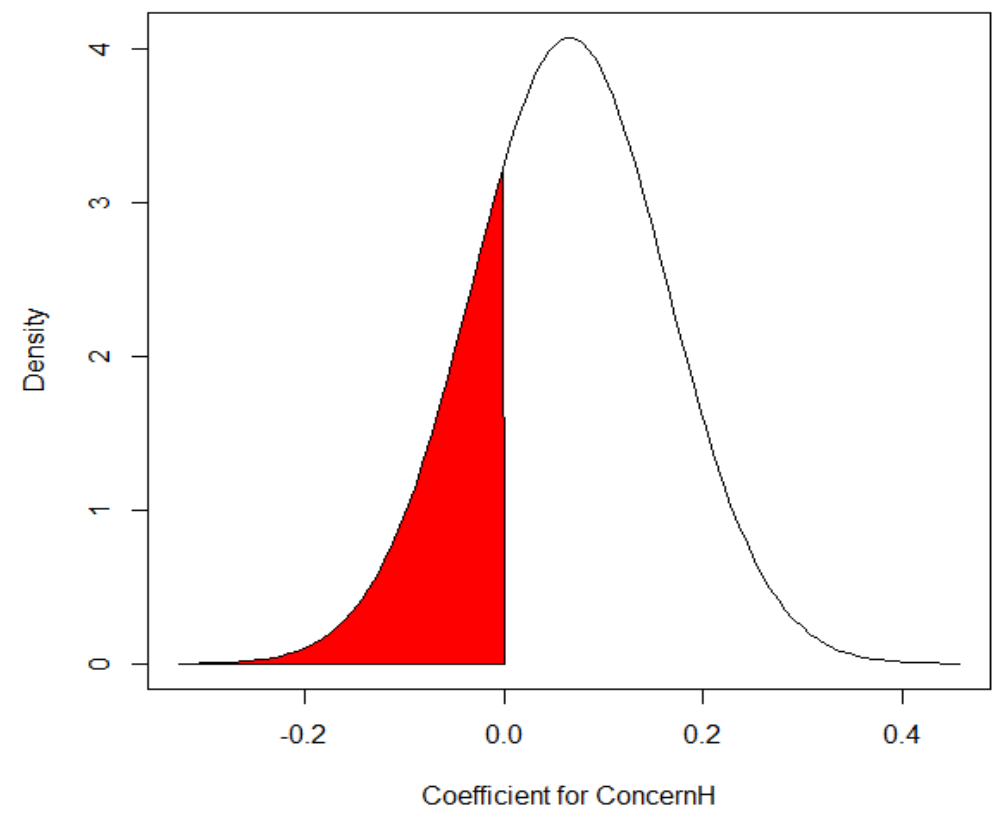

Figure 6: Normal Density Curve for $\beta_{\text {Concern } H}$

The red part represents the probability that $\beta_{\text {ConcernH }}$ is less than 0 , and the rest represents the probability that $\beta_{\text {ConcernH }}$ is larger than 0 . According to the $\mathrm{Z}$ score, $\mathrm{P}\left(\beta_{\text {Concern } H}<0\right)=\mathrm{P}(Z<-0.67)=25.03 \%$ and $\mathrm{P}\left(\beta_{\text {Concern } H}>0\right)=\mathrm{P}(Z>-0.67)=74.97 \%$. Therefore, for $25.03 \%$ of households, the increasing concern about hurricane damage actually decrease their probability to evacuate, whereas for the rest $74.97 \%$ respondents, higher concern about hurricane actually promotes evacuation. The result suggests that household's response is not uniformed, with concern about hurricane threat.

Similar with the random parameter in Model 5 , the parameter for the rate of concern in Model 6 has a mean 0.076 and standard deviation 0.136, which implies that the concern of hurricane damage has negative effect on evacuation for $28.81 \%$ 
of respondents, while it has a positive effect for the rest $71.19 \%$ of households. Although Model 6 has better AIC, BIC, log likelihood value, and predictive probability than Model 2, Model 6 has two significant independent variables less. The presence of elderly and the length that respondent lives in Texas are significant in Model 2 but not in Model 6. In Model 7, $\beta_{\text {ConcernH }}$ follows normal distribution with mean -0.007 and standard deviation $0.208 .51 .3 \%$ of households are more likely to stay at home, when they get increasingly worried about hurricane, whereas the rest respond oppositely. Model 7 has one less significant predictor (Length) than Model 3. Model 8 again has less significant predictors than Model 4. 
Table 1: Description and Summary Statistics of the Variables

\begin{tabular}{|c|c|c|c|c|}
\hline Variable & Description & $N$ & Mean & St.Dev. \\
\hline IfWarnH & $\begin{array}{l}1 \text { if respondent thought the warning before } \\
\text { hurricane helped, } 0 \text { if respondent thought the } \\
\text { warning before hurricane did not help }\end{array}$ & 1001 & 0.635 & 0.482 \\
\hline VolEvacOr & $\begin{array}{l}1 \text { if respondent got voluntary evacuation or- } \\
\text { der, } 0 \text { if respondent did not get voluntary } \\
\text { evacuation order }\end{array}$ & 981 & 0.253 & 0.435 \\
\hline ManEvacOr & $\begin{array}{l}1 \text { if respondent got mandatory evacuation or- } \\
\text { der, } 0 \text { if respondent did not get mandatory } \\
\text { evacuation order }\end{array}$ & 981 & 0.302 & 0.459 \\
\hline JobSecurity & $\begin{array}{l}1 \text { if respondent was laid off because of hurri- } \\
\text { cane, } 0 \text { if respondent was not laid off }\end{array}$ & 774 & 0.098 & 0.298 \\
\hline Elevation & Log-transformed of household elevation & 957 & 3.318 & 0.027 \\
\hline Expenditure & Log-transformed of hurricane expenditure & 669 & 5.757 & 1.33 \\
\hline Children & Number of children under 12 in a household & 1094 & 0.303 & 0.800 \\
\hline Elderly & Number of elderly beyond 65 in a household & 1084 & 0.624 & 0.822 \\
\hline ConcernH & $\begin{array}{l}\text { The rate how respondent concerned about the } \\
\text { threat of hurricane Ike. } 1 \text { if respondent did } \\
\text { not concern at all, } 6 \text { if respondent extremely } \\
\text { concerned }\end{array}$ & 1069 & 4.173 & 1.650 \\
\hline HOwnship & $\begin{array}{l}1 \text { if respondent owns the house, } 0 \text { if respon- } \\
\text { dent does not own the house }\end{array}$ & 1051 & 0.880 & 0.325 \\
\hline
\end{tabular}




\section{Continuation of Table 1}

\begin{tabular}{|c|c|c|c|c|}
\hline Variable & Description & $N$ & Mean & St.Dev. \\
\hline Education & $\begin{array}{l}\text { The education level of respondent. } 1 \text { grade } \\
\text { school, } 2 \text { some high school, } 3 \text { high school, } 4 \\
\text { some college, } 5 \text { college graduate, } 6 \text { graduate } \\
\text { degree }\end{array}$ & 1013 & 4.233 & 1.333 \\
\hline Length & The length that respondent lives in Texas & 1043 & 3.333 & 0.824 \\
\hline Pet & $\begin{array}{l}1 \text { if household owns a pet, } 0 \text { if respondent did } \\
\text { not own a pet }\end{array}$ & 738 & 0.766 & 0.424 \\
\hline Income & $\begin{array}{l}\text { The level of income that subject makes. } 1 \\
\$ 10,000 \text { or less, } 2 \$ 10,001-20,000,3 \$ 20,001- \\
30,000,4 \$ 30,001-40,000,5 \$ 40,001-50,000,6 \\
\$ 50,001-60,000,7 \$ 60,001-70,000,8 \$ 70,001- \\
80,000,9 \$ 80,001-90,000,10 \$ 90,001-100,000\end{array}$ & 616 & 6.287 & 3.516 \\
\hline Race & $\begin{array}{l}\text { The race of subject. } 1 \text { Black or African Amer- } \\
\text { ican, } 2 \text { Asian, } 3 \text { White }\end{array}$ & 992 & 2.663 & 0.732 \\
\hline Distance & $\begin{array}{l}\text { Average spatial distance from household to } \\
\text { hurricane trace }\end{array}$ & 958 & 8.692 & 0.004 \\
\hline Mobile & $\begin{array}{l}1 \text { if respondent lives in mobile house, } 0 \text { if re- } \\
\text { spondent does not live in mobile house }\end{array}$ & 1049 & 0.019 & 0.137 \\
\hline Protection & $\begin{array}{l}1 \text { if respondent had house protection before } \\
\text { hurricane, } 0 \text { if respondent did not have house } \\
\text { protection }\end{array}$ & -10.3 & -19.524 & 0.858 \\
\hline
\end{tabular}


Table 2: Standard Logistic Regression Models

\begin{tabular}{|c|c|c|c|c|}
\hline & Model 1 & Model 2 & Model 3 & Model 4 \\
\hline IfWarnH & $0.486(0.351)$ & $1.004(0.455)^{* *}$ & $0.900(0.539)^{*}$ & $0.552(0.331)^{*}$ \\
\hline VolEvacOr & $1.631(0.425)^{* *}$ & $1.644(0.480)^{* *}$ & $1.446(0.603)^{* *}$ & $1.673(0.416)^{* *}$ \\
\hline ManEvacOr & $2.903(0.503)^{* *}$ & $3.701(0.613)^{* *}$ & $3.397(0.706)^{* *}$ & $3.268(0.478)^{* *}$ \\
\hline JobSecurity & $-1.286(0.565)^{* *}$ & $-0.426(0.655)$ & $-1.805(1.255)$ & $-0.891(0.472)^{*}$ \\
\hline Elevation & $-0.913(0.302)^{* *}$ & $-0.604(0.380)$ & $-0.828(0.444)^{*}$ & $-0.660(0.294)^{* *}$ \\
\hline Expenditure & $-0.742(0.142)^{* *}$ & $-0.770(0.153)^{* *}$ & $-0.801(0.208)^{* *}$ & $-0.782(0.130)^{* *}$ \\
\hline Children & $0.379(0.198)^{*}$ & $0.063(0.218)$ & & \\
\hline Elderly & & $0.563(0.303)^{*}$ & $0.625(0.380)$ & $0.373(0.182)^{* *}$ \\
\hline ConcernH & $0.035(0.102)$ & $0.118(0.128)$ & $0.051(0.150)$ & $0.231(0.101)^{* *}$ \\
\hline HOwnship & $0.803(0.450)^{*}$ & $0.750(0.567)$ & $0.718(0.758)$ & $0.823(0.490)^{*}$ \\
\hline Pet & $-0.119(0.471)$ & & $-0.126(0.686)$ & \\
\hline Income & & $0.030(0.071)$ & $0.032(0.087)$ & \\
\hline Length & & $-0.535(0.268)^{*}$ & $-0.578(0.314)^{*}$ & $-0.381(0.194)^{* *}$ \\
\hline Distance & & & & $-15.539(43.765)$ \\
\hline Education & $-0.125(0.124)$ & $-0.162(0.175)$ & $-0.206(0.190)$ & $-0.181(0.118)$ \\
\hline Protection & & & & $-0.165(.312)$ \\
\hline Mobile & & & & $0.736(0.847)$ \\
\hline Race & & & $-0.466(0.366)$ & \\
\hline Constant & $5.538(1.810)^{* *}$ & $5.199(2.626)^{*}$ & $8.175(3.369)^{* *}$ & $140.373(380.084)$ \\
\hline$N$ & 304 & 247 & 192 & 373 \\
\hline $\log \mathbf{L L}$ & -125.370 & -88.276 & -68.381 & -145.998 \\
\hline Pseudo R2 & 0.405 & 0.483 & 0.485 & 0.423 \\
\hline $\mathrm{AIC}$ & 274.741 & 204.551 & 166.763 & 321.996 \\
\hline $\mathrm{BIC}$ & 319.345 & 253.683 & 215.626 & 380.82 \\
\hline df & 12 & 14 & 15 & 15 \\
\hline Predictive & 0.816 & 0.850 & 0.854 & 0.828 \\
\hline
\end{tabular}

Note: ** refers significance at 0.05 significant level, ${ }^{*}$ refers significance at 0.01 significant level. 
Table 3: Summary of Standard Logistic Regression Models

\begin{tabular}{|l|l|l|l|l|}
\hline & Model 1 & Model 2 & Model 3 & Model 4 \\
\hline IfWarnH & & $1.004(0.455)^{* *}$ & $0.900(0.539)^{*}$ & $0.552(0.331)^{*}$ \\
\hline VolEvacOr & $1.631(0.425)^{* *}$ & $1.644(0.480)^{* *}$ & $1.446(0.603)^{* *}$ & $1.673(0.416)^{* *}$ \\
\hline ManEvacOr & $2.903(0.503)^{* *}$ & $3.701(0.613)^{* *}$ & $3.397(0.706)^{* *}$ & $3.268(0.478)^{* *}$ \\
\hline JobSecurity & $-1.286(0.565)^{* *}$ & & & $-0.891(0.472)^{*}$ \\
\hline Elevation & $-0.913(0.302)^{* *}$ & & $-0.828(0.444)^{*}$ & $-0.660(0.294)^{* *}$ \\
\hline Expenditure & $-0.742(0.142)^{* *}$ & $-0.770(0.153)^{* *}$ & $-0.801(0.208)^{* *}$ & $-0.782(0.130)^{* *}$ \\
\hline Children & $0.379(0.198)^{*}$ & & & \\
\hline Elderly & & $0.563(0.303)^{*}$ & & $0.373(0.182)^{* *}$ \\
\hline ConcernH & & & & $0.231(0.101)^{* *}$ \\
\hline HOwnship & $0.803(0.450)^{*}$ & & & $0.823(0.490)^{*}$ \\
\hline Length & & $-0.535(0.268)^{*}$ & $-0.578(0.314)^{*}$ & $-0.381(0.194)^{* *}$ \\
\hline
\end{tabular}


Table 4: Mixed Logistic Regression Models

\begin{tabular}{|c|c|c|c|c|}
\hline & Mode 5 & Model 6 & Model 7 & Model 8 \\
\hline IfWarnH & $0.446(0.368)$ & $0.868(0.465)^{*}$ & $1.024(0.557)^{*}$ & $0.473(0.344)$ \\
\hline VolEvacOr & $1.424(0.443)^{* *}$ & $1.540(0.528)^{* *}$ & $1.286(0.629)^{* *}$ & $1.498(0.414)^{* *}$ \\
\hline ManEvacOr & $2.665(0.562)^{* *}$ & $3.554(0.686)^{* *}$ & $3.308(0.777)^{* *}$ & $3.034(0.523)^{* *}$ \\
\hline Elevation & $-0.846(0.340)^{* *}$ & $-0.524(0.397)$ & $-0.562(0.453)$ & $-0.842(0.302)^{* *}$ \\
\hline JobSecurity & $-1.387(0.596)^{* *}$ & $-0.543(0.681)$ & $-2.268(1.142)^{* *}$ & $-0.992(0.506)^{* *}$ \\
\hline Expenditure & $-0.814(0.165)^{* *}$ & $-0.880(0.204)^{* *}$ & $-0.842(0.222)^{* *}$ & $-0.859(0.153)^{* *}$ \\
\hline Children & $0.405(0.219)^{*}$ & $0.049(0.236)$ & & \\
\hline Elderly & & $0.318(0.367)$ & $0.218(0.428)$ & $0.296(0.227)$ \\
\hline HOwnship & $1.187(0.522)^{* *}$ & $1.153(0.787)$ & $1.287(0.903)$ & $0.734(0.578)$ \\
\hline Pet & $-0.575(0.423)$ & & $-0.411(0.616)$ & \\
\hline Income & & $0.032(0.078)$ & $0.041(0.096)$ & \\
\hline Length & & $-0.353(0.324)$ & $-0.206(0.399)$ & $-0.172(0.237)$ \\
\hline Distance & & & & $-69.794(53.661)$ \\
\hline Education & $-0.140(0.130)$ & $-0.158(0.192)$ & $-0.184(0.215)$ & $-0.202(0.130)$ \\
\hline Protection & & & & $-0.007(0.334)$ \\
\hline Mobile & & & & $0.994(1.459)$ \\
\hline Race & & & $-0.441(0.370)$ & \\
\hline Constant & $5.487(1.952)^{* *}$ & $5.033(2.483)^{* *}$ & $6.525(3.255)^{* *}$ & $211.819(422.590)$ \\
\hline \multicolumn{5}{|l|}{ RANDOM } \\
\hline ConcernH & $0.066(0.098)^{a}$ & $0.076(0.136)^{a}$ & $-0.007(0.208)^{a}$ & $0.218(0.096)^{a}$ \\
\hline$N$ & 304 & 247 & 192 & 373 \\
\hline $\log \mathbf{L L}$ & -107.826 & -78.185 & -59.760 & -126.725 \\
\hline AIC & 243.651 & 188.370 & 153.520 & 287.450 \\
\hline BIC & 293.820 & 242.813 & 207.125 & 351.931 \\
\hline df & 14 & 16 & 17 & 17 \\
\hline Predictive & 0.827 & 0.856 & 0.855 & 0.841 \\
\hline
\end{tabular}

Note: ${ }^{* *}$ refers significance at 0.05 significant level, ${ }^{*}$ refers significance at 0.01 significant level. 
Table 5: Summary of Mixed Logistic Regression Models

\begin{tabular}{|l|l|l|l|l|}
\hline & Mode 5 & Model 6 & Model 7 & Model 8 \\
\hline IfWarnH & & $0.868(0.465)^{*}$ & $1.024(0.557)^{*}$ & \\
\hline VolEvacOr & $1.424(0.443)^{* *}$ & $1.540(0.528)^{* *}$ & $1.286(0.629)^{* *}$ & $1.498(0.414)^{* *}$ \\
\hline ManEvacOr & $2.665(0.562)^{* *}$ & $3.554(0.686)^{* *}$ & $3.308(0.777)^{* *}$ & $3.034(0.523)^{* *}$ \\
\hline Elevation & $-0.846(0.340)^{* *}$ & & & $-0.842(0.302)^{* *}$ \\
\hline JobSecurity & $-1.387(0.596)^{* *}$ & & $-2.268(1.142)^{* *}$ & $-0.992(0.506)^{* *}$ \\
\hline Expenditure & $-0.814(0.165)^{* *}$ & $-0.880(0.204)^{* *}$ & $-0.842(0.222)^{* *}$ & $-0.859(0.153)^{* *}$ \\
\hline Children & $0.405(0.219)^{*}$ & & & \\
\hline HOwnship & $1.187(0.522)^{* *}$ & & & \\
\hline
\end{tabular}




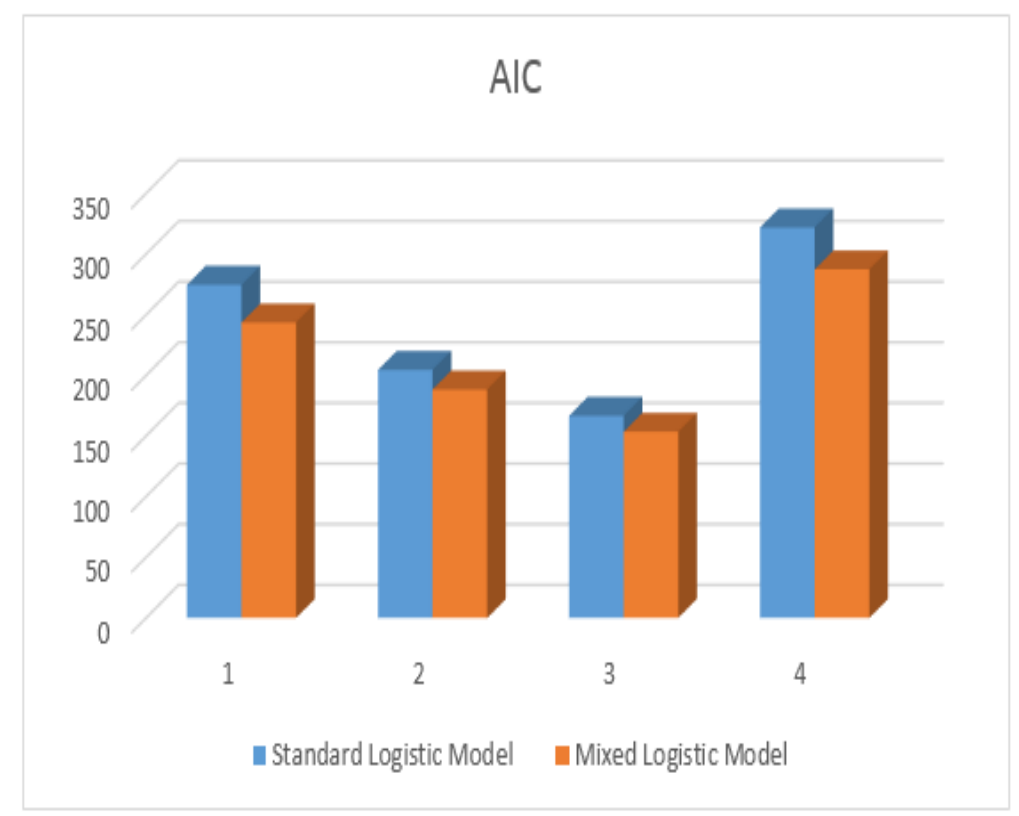

Figure 7: Plot of AIC values

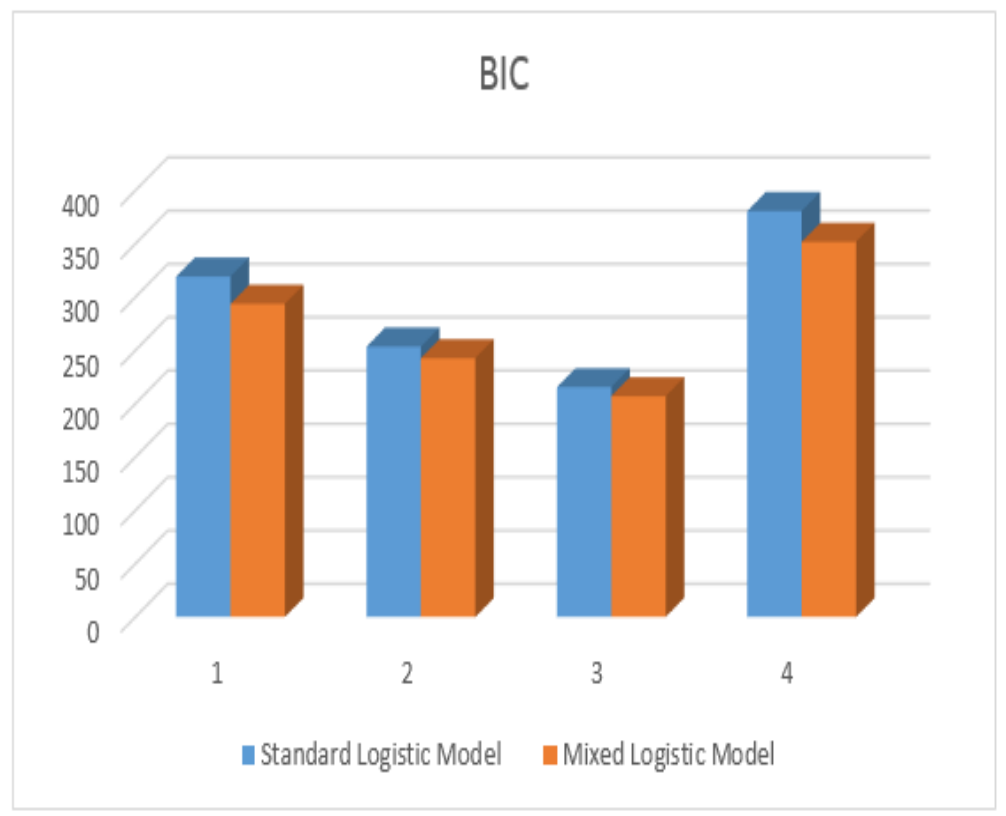

Figure 8: Plot of BIC values 


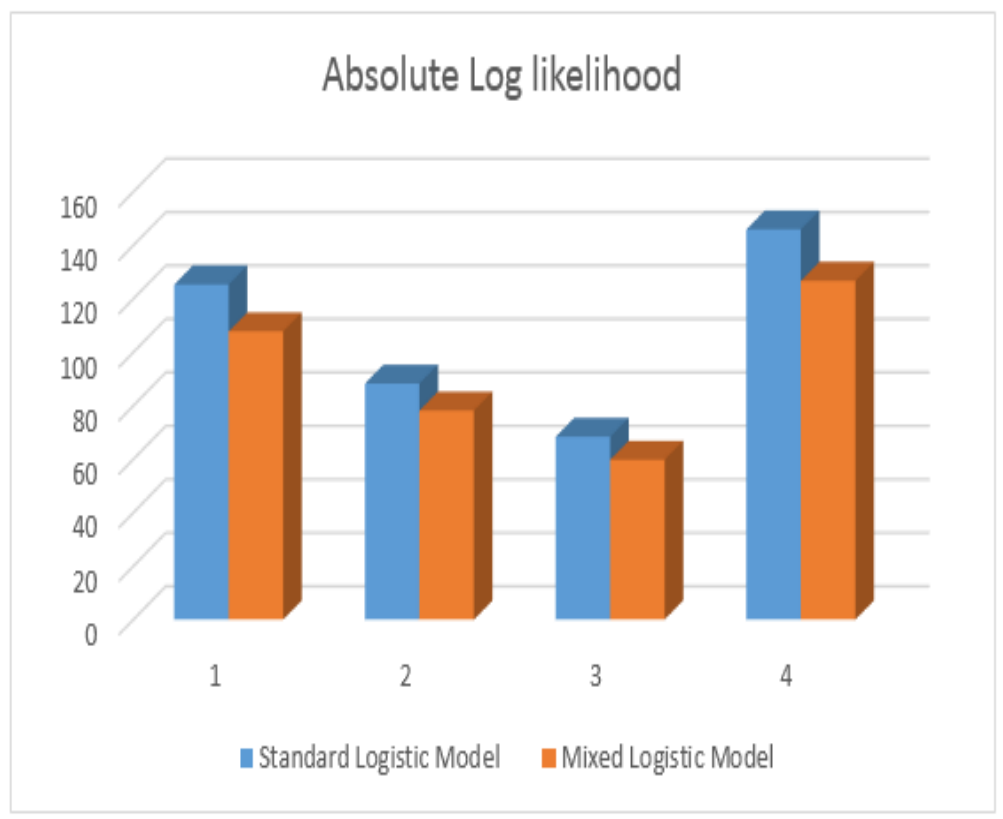

Figure 9: Plot of Absolute Log Likelihood Values

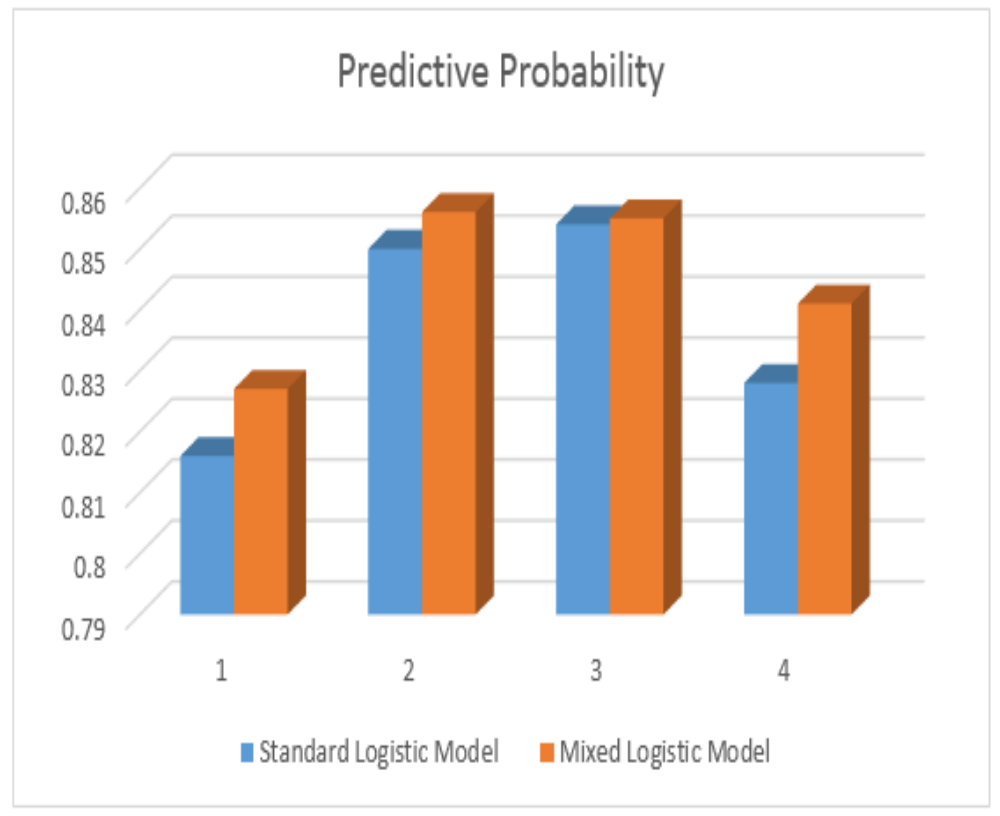

Figure 10: Plot of Predictive Probability Values 


\section{Summary and Future Research}

In my research, both standard logistic model and mixed logistic model are reported. Mixed logistic modeling approach offers a methodological flexibility that can be used to model household evacuation decisions. Several factors are found to influence household's decision to evacuate or stay at home, among which presence of children in a family, notice of evacuation order, ownership of the house and perception of the effect of hurricane warning have a positive influence on evacuation decision. However, households in low elevation area and households in unemployment status are more likely to stay at home. Expenditure is also found to negatively influence evacuation decision. Among the standard logistic models, Model 3 performs better in the sense of goodness of fit criterion. For all mixed logistic models, one risk perception factor is assumed to be normally distributed random parameter to represent the associated heterogeneities in household's evacuation behavior. Adding random factors greatly reduces the AIC, BIC, and absolute Log Likelihood value,and improves predictive probability. Of all the four mixed logistic models, Model 7 has smallest AIC, BIC, and absolute value of Log likelihood and largest predictive probability. Therefore, considering all the measurements above, Model 7 performs relatively better. In the future, one might generate more related predictors, such as distance from households to coastline, and add them to the analysis. Also, one may try for crossvalidation technique to assess the result of the models which can be generalized to other independent data set. 


\section{REFERENCES}

Baker, E. J. (1979). Predicting response to hurricane warnings: A reanalysis of data from four studies. Mass Emerg. 4(1), 9-24.

Baker, E. J. (1991). Evacuation behavior in hurricanes. Int. J. Mass Emerg. Disasters, 9(2), 287-310.

Cross, J. (1979). The association between previous residence and hurricane hazard perception and adjustments. Paper presented at the 75th Annual Meeting of the Association of American Geographers, Philadelphia.

Drabek, T.E. (1999). Disaster-induced employee evacuation. Program on environment and behavior, monograph No. 60, Institute of Behavioral Sciience, Huniversity of Colorado, Boulder, CO.

Cox, Robert F., Issa, R.R., Ligator, J. (2006). Top ten Florida residential building code violations.

Dow, K., and Cutter, S.L. (1998). "Crying wolf: Repeat responses to hurricane evacuation orders." Coastal Manage.,26(4), 237-252.

Dash, N., and H. Gladwin, 2007: Evacuation decision making and behavioral responses: Individual and household. Nat. Hazards Rev., 8, 6977.

Dehring, Carolyn A., Halek, M. (2013). Coastal building codes and hurricane damage. Land Economics. 89(4), 597-613.

Fischer, H. W., Stine, G. F., Stoker, B.L., Trowbridge, M. L., and Drain, E. M. (1995). Evacuation behavior: Why do some evacuate, while others do not? A case study of the Ephrata, Pennsylvania, (USA) evacuation. Disaster Prev. Manage., $4(4), 30-36$.

Hasan, S., Ukkusuri, S., Gladwin, H., Murray-Tuite, P. (2010). Behavioral model to understand household-level hurricane evacuation decision making. Journal of Transportation Engineering, 137(5), 341-348.

Pan, Qisheng. (2012). Estimating the economic losses of hurricane IKE in the greater Houston region. .

Peng, Chao-Ying J., Lee, K.L., Ingersoll,G.M. (2002). An Introduction to logistic regression analysis and reporting. The Journal of Educational Research. 96(1), $3-14$. 
Peng, C.Y., Manz, B.D., Keck,J. (2001). Modeling categorical variables by logistic regression. Ameriican Journal of Health Behavior, 25(3), 278-284

Pielke Jr, R. A., Gratz, J., Landsea, C. W., Collins, D., Saunders, M. A., Musulin, R. (2008). Normalized hurricane damage in the United States: 1900-2005. Natural Hazards Review. 9(1), 29-42.

Train, K. (2003). Discrete choice methods with simulation, Cambridge University Press, Cambridge, UK.

Whitehead, J. C., Edwards, B., Van Willigen, M., Maiolo, J. R., Wilson, K., and Smith, K. T. (2000). Heading for higher ground: Factors affecting real and hypothetical hurricane evacuation behavior. Global Environ. Change Part B: Environ. Hazards, 2(4), 133-142. 